\title{
Analysis of Local Vibration for High-Speed Railway Bridge Based on Finite Element Method
}

\author{
Wenjun Luo*
}

\section{Engineering Research Center of Railway Environment Vibration and Noise Ministry of Education, East China Jiaotong University, Nanchang, 330013, China}

\begin{abstract}
Based on the theory of vehicle track coupling dynamics, the local vibration of the high-speed railway box girder is analyzed by the Finite Element Method and the model is simulated with the solid elements. Through the study of vibration characteristics of the selected 6 sensitive points, the local vibrations in different parts of the box girder are figured out. It is compared the response of the time domain and frequency domain in different parts of the cross section on different train speeds. Furthermore, the influence of track irregularity of local vibration response is analyzed. The results show that the track irregularity is the main factor causing local vibration. At last, the effects of local vibration on the boundary conditions are discussed. The response of top panel, floor panel and web panel were different and the flange panel was similar between the simple supported beam and the fixed beam.
\end{abstract}

Keywords: Boundary conditions, bridge, local vibration, finite element method, track irregularity.

\section{INTRODUCTION}

The low frequency global vibration and the high frequency local vibration are producing due to high-speed trains passing on railway viaducts. The local vibration is the main source of structure-borne noise [1]. The researches of global vibration were shown clearly in many previous papers [2]. However, the researches of local vibration were focus on the fundamental propagating law and producing mechanism. In this study the local vibration of the high-speed railway box girder is analyzed by the FEM, based on the theory of vehicle track coupling dynamics.

\section{COMPUTATIONAL MODEL}

\subsection{Finite Element Model}

The viaduct is modeled with a simple supported box girder which is $32 \mathrm{~m}$ long and used in a high speed railway. The structure size is shown in the Fig. (1).

The box girder and the CRTSII track slab are simulated with solid 45 element, the rail is simulated with beam 188 , the fastening and CA mortar is simulated with combine15, the finite element model is shown in Fig. (2). The bridge pier and some attached components are not considered, Table $\mathbf{1}$ show the relevant parameters.

\subsection{Vehicle-Ballastless Track-Bridge Coupling System Model}

The new Vehicle-Ballastless track-bridge coupling system is used in this paper [3], the vehicle is modeled to be four driving wheel elements with a secondary suspension system. Car body, bogie and wheel set are considered to be rigid body, vertical motion is only concerned and the contact between wheel and rail is elastic. The analysis is divided in even track and uneven track. The vehicle is CRH3 and the speeds are considered from 230 to $410 \mathrm{~km} / \mathrm{h}$. We can get the wheel/rail forces in different conditions. When the track is even, the wheel/rail forces are unchanged with vehicle speed increasing. The stable value is floating in a small area near 69.7 KN [4].

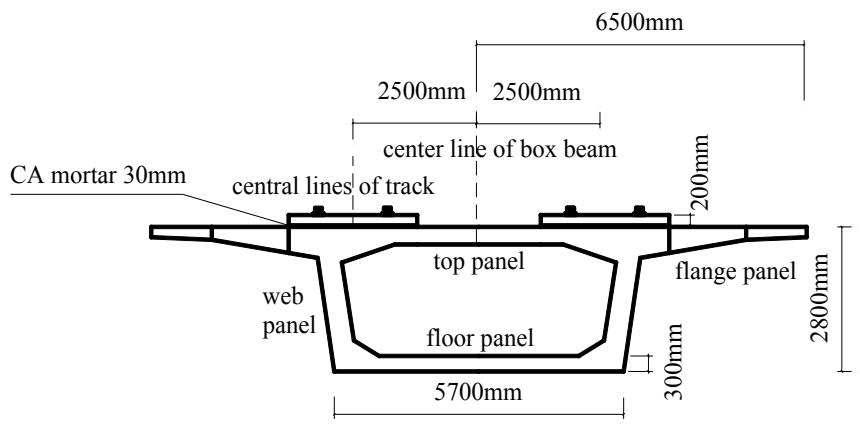

Fig. (1). Structure size.

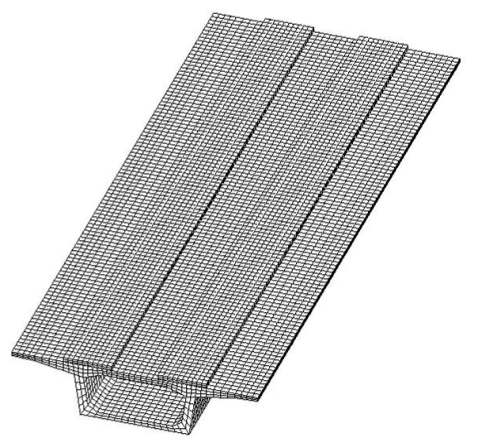

Fig. (2). Finite element model. 
In the uneven track condition, the German high-speed low disturbance line is used to be the irregularity excitation. The irregularity sample is simulated in the method studied by Chen Guo [5]. The maximum wheel/rail forces in different speeds are listed in Table 2. It is shown that the forces are increasing with the speeds.

Table 1. The parameters of ballastless track and box girder.

\begin{tabular}{|c|c|}
\hline Parameters & Value \\
\hline \hline Steel Rail density $\mathrm{kg} / \mathrm{m} 3$ & 7800 \\
\hline Track slab density $\mathrm{kg} / \mathrm{m} 3$ & 2500 \\
\hline Box girder density $\mathrm{kg} / \mathrm{m} 3$ & 2600 \\
\hline Stiffness of tie N/m & $7.8 \mathrm{e} 7$ \\
\hline Damping of CA mortar N•s/m & $8.3 \mathrm{e} 4$ \\
\hline Poisson ratio of slab & 0.3 \\
\hline Poisson ratio of slab & 0.176 \\
\hline Poisson ratio of girder & 0.2 \\
\hline Stiffness of CA N/m & $1.2 \mathrm{e} 9$ \\
\hline Young's modulus of rail GP & 210 \\
\hline Young's modulus of slab GP & 39 \\
\hline Damping of CA mortar GP & 34.5 \\
\hline Damping of ties N•s/m & $5 \mathrm{e} 4$ \\
\hline
\end{tabular}

Then the forces were loaded them on the rail model based on the wheel position.

\subsection{The Natural Analysis of Box Girder}

By the modal analysis of the box girder, the natural vibration frequency bands before 500 can be computed, the frequency range from 0 to $401.2 \mathrm{~Hz}$. The vibration frequency and modes before 10 are listed in Table 3 .

It is shown that the first six modes are the global vibration and the remaining modes are all attributed to the local vibration. Thus the local vibration is high frequency vibration relatively.

\section{THE INFLUENCE OF TRACK STATUS ON THE LOCAL VIBRATION}

In the analysis of the transient dynamic behavior, 6 sensitive points at the mid-span section are selected. And the modal superposition method is used to calculate [6] based on the wheel position.

Table 2. Maximum of wheel/rail forces.

\subsection{Even Track State}

(1) Through the analysis of the result, the maximum acceleration and Root Mean Square (RMS) of acceleration of all sensitive points in different velocities are shown in Fig. (5).

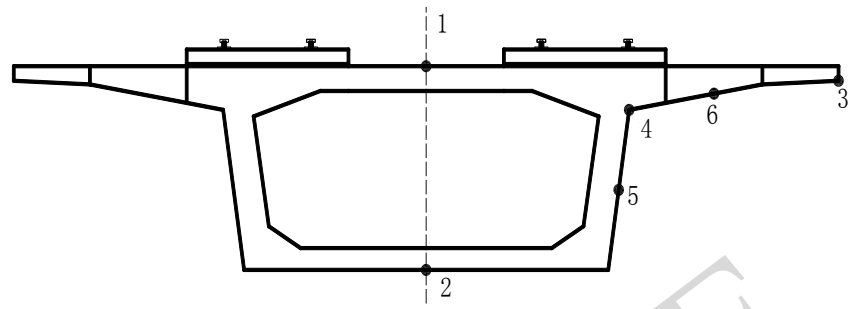

Fig. (4). The distribution of sensitive points.

The above figure shows that the maximums acceleration of all points are increasing gradually with the increasing of speeds. As known, the RMS of acceleration is an important indicator which can reflect the vibration very well. Fig. (5.1) show that all RMS are increasing with the speeds and the increasing rate of the six points are consistent. On the whole, an ascending order of the acceleration of the points at same speed is: point two, point one, point four, point five (four and five are similar), point six, point three.

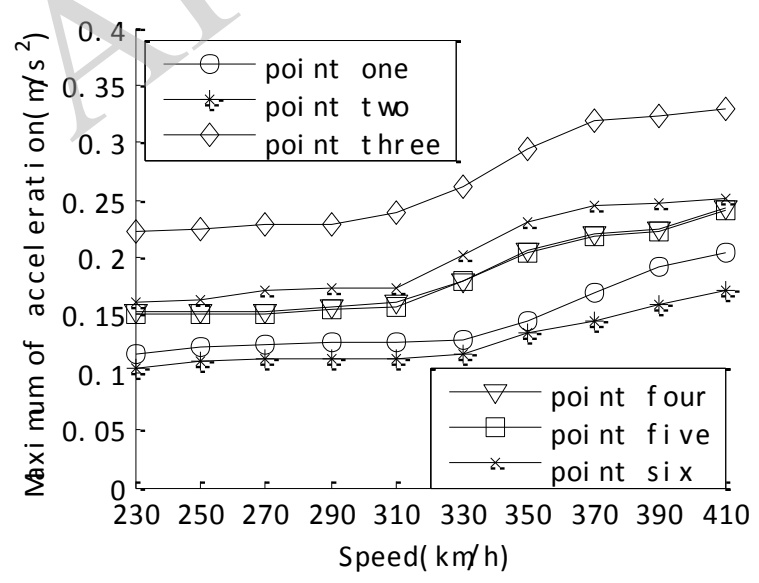

Fig. (5.1). The maximum acceleration.

(2) The frequency analysis of the acceleration at the speed $(230 \mathrm{~km} / \mathrm{h}, 270 \mathrm{~km} / \mathrm{h}, 310 \mathrm{~km} / \mathrm{h}, 350 \mathrm{~km} / \mathrm{h}, 390$ $\mathrm{km} / \mathrm{h}$ ) is shown in Fig. (6).

The figures show that the dominant frequency of the points range from 0 to $189 \mathrm{~Hz}$. When it is in the $0-22 \mathrm{~Hz}$ band, the vibration models in this frequency band belong to the global forced vibration. As it is more than $189 \mathrm{~Hz}$, the amplitude is so small that the part can be neglected. At one

\begin{tabular}{|c|c|c|c|}
\hline Speed (km/h) & Maximum of Wheel/Rail Forces (KN) & Speed (km/h) & Maximum of Wheel/Rail Forces (KN) \\
\hline \hline 230 & 113.7 & 330 & 137.3 \\
\hline 250 & 119.1 & 350 & 142.1 \\
\hline 270 & 124.1 & 370 & 147.5 \\
\hline 290 & 128.8 & 390 & 152.9 \\
\hline 310 & 133.1 & 410 & 158.4 \\
\hline
\end{tabular}


speed, the peaks of vibration of all points appear at the same frequencies. By contrast with the result of natural analysis, we can figure out that the frequencies of local vibration focus on 22-189 Hz.

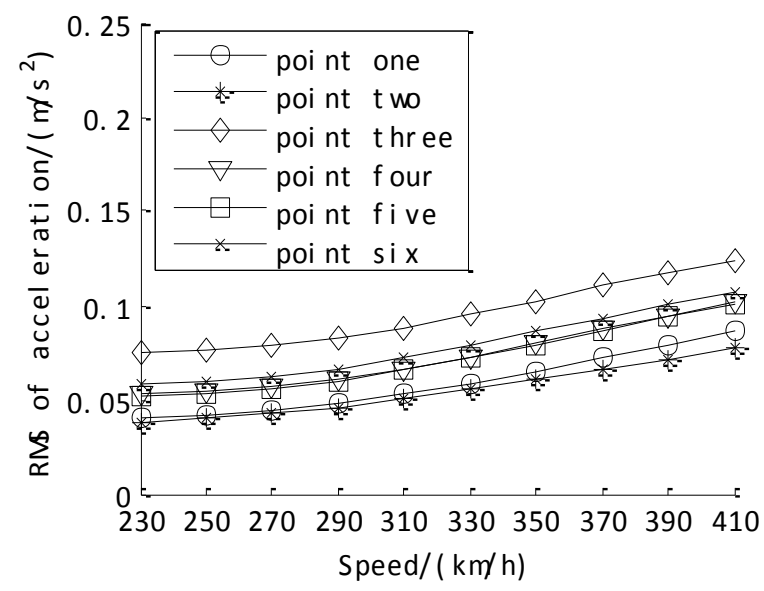

Fig. (5.2). Root Mean Square of acceleration.
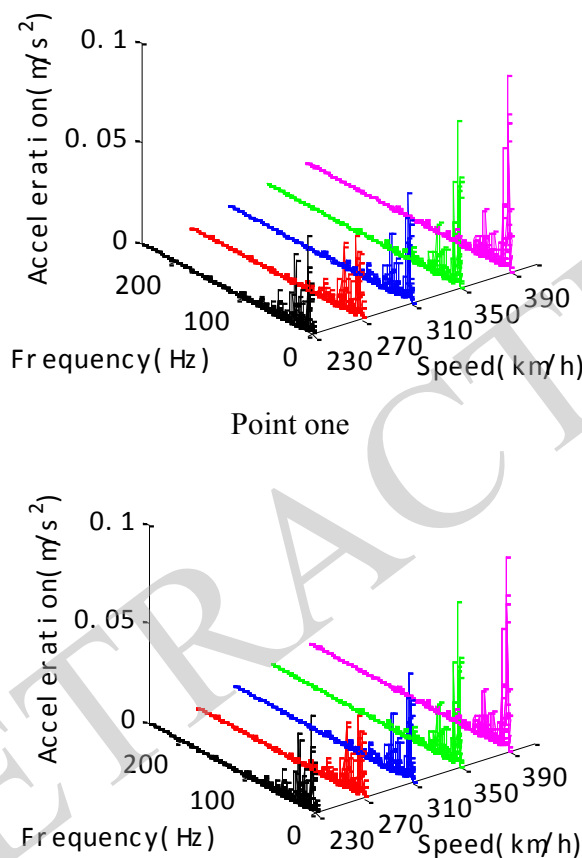

Point three

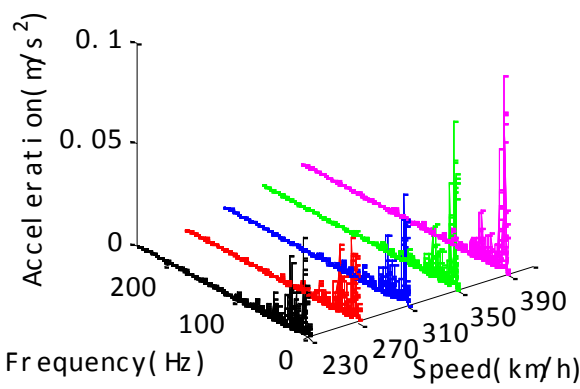

Point five
Table 3. The first 10 order modal description.

\begin{tabular}{|c|c|c|}
\hline $\begin{array}{c}\text { Modal } \\
\text { Order }\end{array}$ & $\begin{array}{c}\text { Natural Frequency/ } \\
\text { Hz Frequency/Hz }\end{array}$ & Vibration Type Description \\
\hline \hline 1 & 5.61 & The first-order vertical bending \\
\hline 2 & 5.88 & Dumping of box girder \\
\hline 3 & 10.58 & The second-order vertical bending \\
\hline 4 & 12.67 & The first-order torsion \\
\hline 5 & 14.71 & The second-order torsion \\
\hline 6 & 17.54 & Ant symmetric bending \\
\hline 7 & 22.81 & Local vibration \\
\hline 8 & 24.60 & Local vibration \\
\hline 9 & 26.35 & Local vibration \\
\hline 10 & 26.91 & Local vibration \\
\hline
\end{tabular}

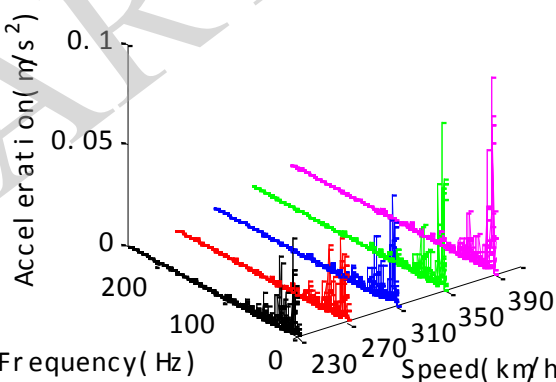

Point two

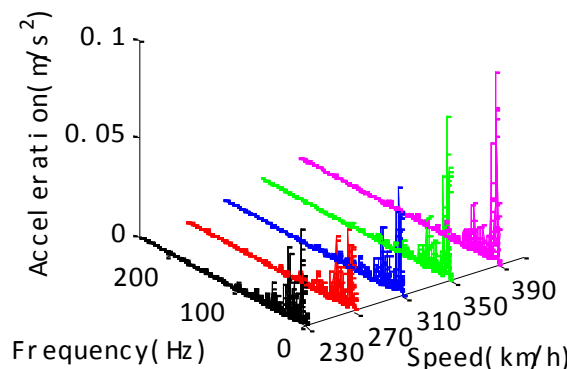

Point four

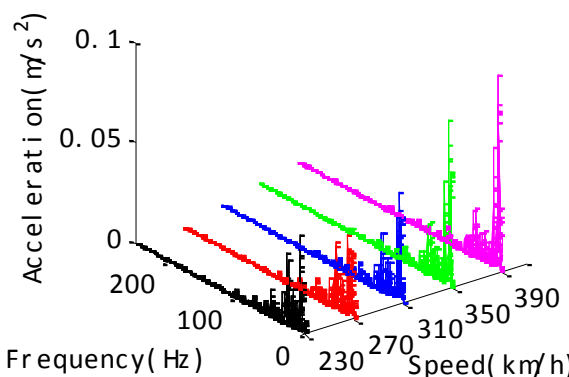

Point six

Fig. (6). The frequency spectrums of the points. 


\subsection{Track Irregularity State}

In this state, the maximum acceleration and RMS acceleration of all sensitive points in different velocities is of shown in Fig. (7).

(2) Compared the Fig. (7.1) with the Fig. (7.2), the accelerations in track irregularity is 10 times that of them

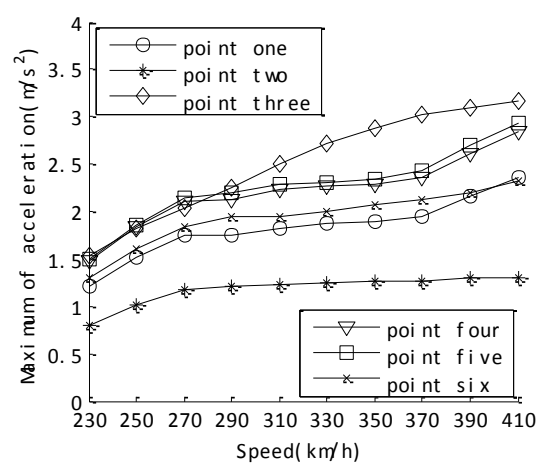

Fig. (7.1). The maximum acceleration.
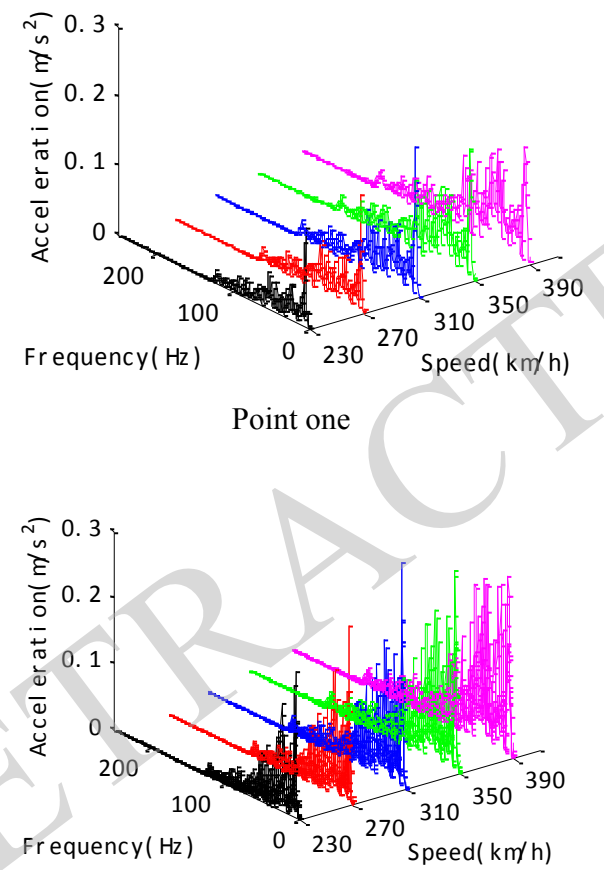

Point three

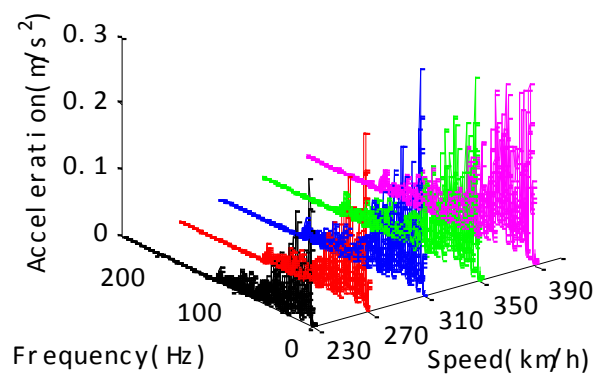

Point five

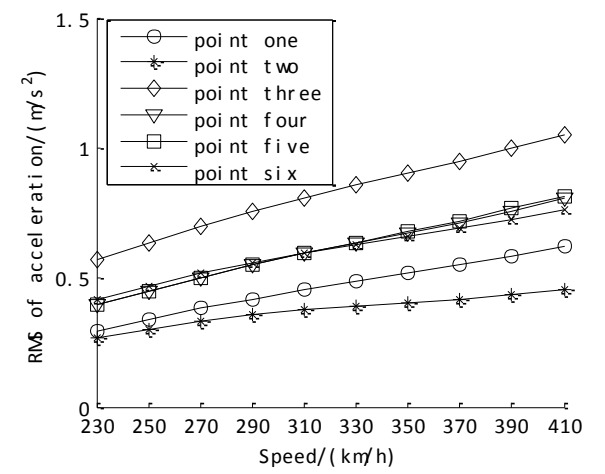

Fig. (7.2). Root Mean Square of acceleration.

in track even. It can figure out that track irregularity is the main factor caused the local vibration. When the speed is $410 \mathrm{~km} / \mathrm{h}$, the acceleration of point three is 3.37 $\mathrm{m} / \mathrm{s} 2$ and the acceleration of point two is $1.09 \mathrm{~m} / \mathrm{s} 2$. The values don't exceed the value of the standard $-5 \mathrm{~m} / \mathrm{s} 2$.

It is shown that the RMS of point three is larger significantly than other points. Thus as the high speed train load on the box girder, the flange panel of the girder vibrates

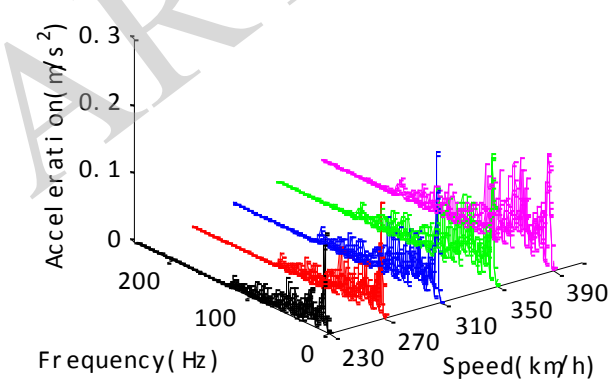

Point two

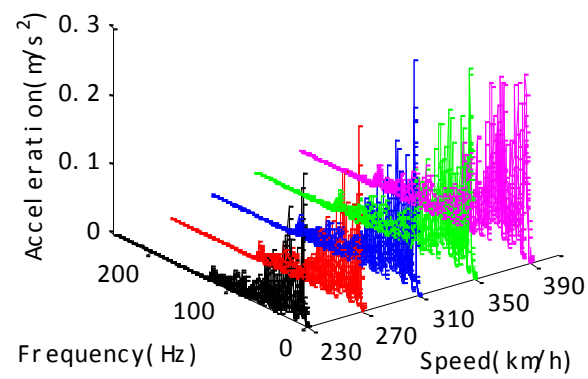

Point four

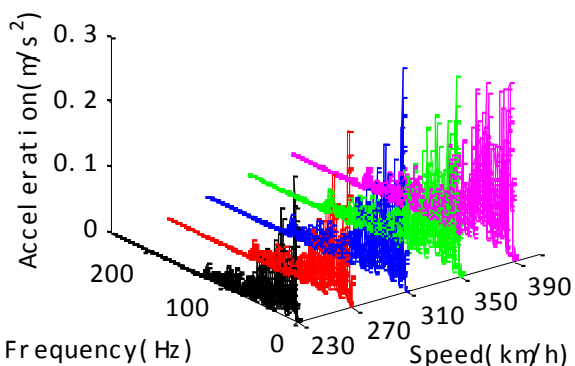

Point six

Fig. (8). The frequency spectrums of six sensitive points. 
more strongly than other parts. The amplitude of point two is the least.

(3) At this status, the frequency analysis of the acceleration at speed $(230 \mathrm{~km} / \mathrm{h}, 270 \mathrm{~km} / \mathrm{h}, 310 \mathrm{~km} / \mathrm{h}$, $350 \mathrm{~km} / \mathrm{h}, 390 \mathrm{~km} / \mathrm{h}$ ) is shown in Fig. (8).

The figures show that the dominant frequency of the points range from 0 to $199 \mathrm{~Hz}$. From 0 to $22 \mathrm{~Hz}$, the peaks appear the same as the forward status and it is the global forced vibration. Compared to the even track, the distribution intervals of local vibration extend a little. Table 4 lists the dominant frequency of local vibration between the irregularity track and even track.

Table 4. Frequency interval distribution.

\begin{tabular}{|c|c|c|}
\hline \multirow{2}{*}{ Speed } & \multirow{2}{*}{ Dominant Frequency of Local Vibration (Hz) } \\
\cline { 2 - 3 } & Even Status & Irregularity \\
\hline \hline 230 & $22-108$ & $22-120$ \\
\hline 250 & $22-117$ & $22-128$ \\
\hline 270 & $22-126$ & $22-136$ \\
\hline 290 & $24-135$ & $24-148$ \\
\hline 310 & $24-144$ & $24-156$ \\
\hline 330 & $24-153$ & $24-167$ \\
\hline 350 & $26-162$ & $26-176$ \\
\hline 370 & $26-171$ & $26-184$ \\
\hline 390 & $28-180$ & $28-191$ \\
\hline 410 & $28-189$ & $28-199$ \\
\hline
\end{tabular}

\section{INFLUENCE OF BOUNDARY CONDITION ON LOCAL VIBRATION}

In this paper, two kinds of boundary condition-simple support condition and fixed condition-are compared. The fixed beam refer to a beam that the six degrees of freedom of the both ends are constrained. Table 5 lists the first ten natural frequencies. It is shown that the frequencies of the fixed boundary condition are larger than simple support condition.

Table 5. The natural frequencies of the first ten order.

\begin{tabular}{|c|c|c|}
\hline \multirow{2}{*}{ Modal Order } & \multicolumn{2}{|c|}{ The Natural Frequencies (Hz) } \\
\cline { 2 - 3 } & Simple Support & Fixed \\
\hline \hline 1 & 5.61 & 6.43 \\
\hline 2 & 5.87 & 6.97 \\
\hline 3 & 10.58 & 12.69 \\
\hline 4 & 12.67 & 13.26 \\
\hline 5 & 14.7 & 14.77 \\
\hline 6 & 17.54 & 19.68 \\
\hline 7 & 22.81 & 23.05 \\
\hline 8 & 23.6 & 24.61 \\
\hline 9 & 25.35 & 26.48 \\
\hline 10 & 26.9 & 27.96 \\
\hline
\end{tabular}

Table 6 lists the maximum acceleration of all the points on the two conditions. As the table show, the behavior of fixed girder is weaker than the simple support girder overall. Based on the third row which shows the reducing percentage, we summed that the influence on the point three and six is not obvious. Therefore the fixed girder is valid to reduce the local vibration behavior of top panel, floor panel and web panel. And the effects on flange panel of both sides are not obvious.

Table 6. Maximum acceleration of the points.

\begin{tabular}{|c|c|c|c|}
\hline \multirow{2}{*}{$\begin{array}{c}\text { Point } \\
\text { Number }\end{array}$} & \multicolumn{2}{|c|}{ Maximum Acceleration (m/s2) } & \multirow{2}{*}{$\begin{array}{c}\text { Reducing } \\
\text { Percentage (\%) }\end{array}$} \\
\cline { 2 - 3 } & Simple Support & Fixed & \\
\hline \hline Point one & 1.52 & 1.27 & 16.22 \\
\hline Point two & 1.02 & 0.90 & 11.49 \\
\hline Point three & 2.09 & 2.13 & 1.6 \\
\hline Point four & 1.83 & 1.49 & 18.31 \\
\hline Point five & 1.86 & 1.52 & 18.17 \\
\hline Point six & 1.60 & 1.53 & 4.12 \\
\hline
\end{tabular}

(1) Through the analysis of local vibration on the finite element model, the vibration of flange panel is strongest and the floor panel is the weakest at the same speed and track status.

(2) The dominant frequency interval of the local vibration is focus on 22-199 Hz. The interval will extend with the speed increasing.

(3) Track irregularity is the main factor to cause the local vibration. It is great that the influence of the track irregularity on the local vibration.

(4) The effects of local vibration on the boundar -y conditions are discussed. The response of top panel, floor panel and web panel were different and the flange panel was similar between the simple supported beam and the fixed beam.

\section{CONFLICT OF INTEREST}

The author confirms that this article content has no conflict of interest.

\section{ACKNOWLEDGEMENTS}

The research of this project is partly supported by National Natural Science Foundation (51468021).

\section{REFERENCES}

[1] Y. Y. Lee, K. W. Ngai, and C. F. Ng, "The local vibration modes due to impact on the edge of a viaduct", Applied Acoustics, vol. 65, pp. 1077-1093, 2004.

[2] R. Crockett, and J. R. Pyke, "Viaduct design for minimization of direct and structure-radiated train noise", Journal of Sound and Vibration, vol. 231, no. 3, pp. 883-897, 2000. 
[3] W. J. Shao, L. Y. Liu, and B. Zhang, "Analysis of dynamic response to simple-supported beam under high speed train", in ISMR'2012-Proceedings of the Third International Symposium on Innovation \& Sustainability of Modern Railway, Nanchang, East China Jiaotong University, pp. 138-142, 2012.

[4] W. J. Luo, X. Y. Lei, and S. L. Lian, "Analysis on Vibration of Ballastless Track Bridge System Based on Hybrid FE SEA Method", vol. 35, no. 8, 2013.
[5] G. Chen, and W. M. Zhai, "Numerical Simulation of the Stochastic Process of Railway Track Irregularities", Journal of southwest Jiaotong University, vol. 34, no. 2, pp. 138-141, 1999.

[6] Q. Li, Vehicle-bridge/rail coupling vibration refine analysis in theory and applications, Shanghai: Tongji University, 2008.

(C) Wenjun Luo; Licensee Bentham Open.

This is an open access article licensed under the terms of the Creative Commons Attribution Non-Commercial License (http://creativecommons.org/licenses/by-nc/3.0/) which permits unrestricted, non-commercial use, distribution and reproduction in any medium, provided the work is properly cited. 